\begin{tabular}{|c|l|}
\hline Title & Susceptibility of bovine osteopontin to chymosin \\
\hline Author(s) & Kumura, Haruto; Miura, A tsushi; Sato, Eriko; Tanaka, Tetsuya; Shimazaki, Kei-ichi \\
\hline Citation & Journal of Dairy Research, 71(4), 500-504 \\
https://doi.org/10.1017/S002202990400391 \\
\hline Issue Date & 200411 \\
\hline Doc URL & http://hdl.handle.net/2115/5724 \\
\hline Rights & Copyright $\odot$ 2004 Cambridge University Press \\
\hline Type & article \\
\hline File Information & JDR71-4.pdf \\
\hline
\end{tabular}

Instructions for use 


\title{
Susceptibility of bovine osteopontin to chymosin
}

\author{
Haruto Kumura*, Atsushi Miura, Eriko Sato, Tetsuya Tanaka and Kei-ichi Shimazaki \\ Laboratory of Dairy Science, Research Group of Animal Product Science, Division of Bioresources and Product Science, \\ Graduate School of Agriculture, Hokkaido University, Sapporo-shi 060-8589, Japan
}

Received 20 August 2003 and accepted for publication 11 December 2003

Keywords: bovine osteopontin, colostrum, chymosin.

Osteopontin (OPN) is an acidic phosphorylated glycoprotein found in many tissues and physiological fluids. Bovine OPN is a mature protein comprising 262 amino acids with a calculated molecular weight of $29 \mathrm{kDa}$. However, SDS-PAGE analysis reveals that the protein isolated from milk migrates to a molecular mass of $60 \mathrm{kDa}$ (Sørensen \& Petersen, 1993; Bayless et al. 1997). Bovine milk OPN is phosphorylated at 27 serine residues and one threonine residue (Sorensen et al. 1995); three O-glycosylated threonines were also identified, but no asparagine residues were glycosylated in spite of the presence of three putative $\mathrm{N}$-glycosylation sites. In contrast, eight phosphates are recognized in bovine bone OPN (Salih et al. 1996), and 12 phosphoserines and one phosphothreonine are proposed in addition to five O-linked oligosaccharides and at most one $\mathrm{N}$-linked oligosaccharide in the case of rat bone OPN (Prince et al. 1987). Thus, the possibility of tissue or species-specific differences in post-translational modification has been discussed.

A number of reports discuss the function of OPN, including cell adhesion, calcium remodelling, cell signalling and cellular transformation, and these functions have been extensively reviewed (Butler et al. 1996; Sodek et al. 2000). In mammary gland, high levels of OPN expression are observed in early lactation and involution (Rittling \& Novick, 1997). Nemir et al. (2000) describe the biological significance of OPN in mammary gland differentiation. It is claimed that OPN is more abundant in colostrum (Uede et al. 1997), which contains relatively high levels of proteins that confer immunological defence in newborns, such as lactoferrin, lactoperoxidase and immunoglobulins. However, little attention has been paid to the biological significance of OPN in the milk supplied to newborns. In addition, we lack fundamental information on the concentration and molecular properties of OPN, which is necessary to determine its possible roles in mammary secretions.

In this study, we used immunodetection to measure OPN in bovine mammary secretions during early lactation. Furthermore, because it appears exclusively in the

\footnotetext{
*For correspondence; e-mail: kumura@anim.agr.hokudai.ac.jp
}

abomasum of newborn ruminants, we examined the susceptibility of OPN to chymosin. In addition, some molecular properties including deletion and glycosylation are also discussed.

\section{Materials and Methods}

\section{Samples}

Samples of colostrum and milk were obtained individually from the first 10 milkings post partum (days 1-5 of lactation) from seven Holstein-Friesian cows from the Hokkaido University Experimental Farm. Colostrum was obtained immediately after parturition. The cows were milked twice daily. Purification of OPN was carried out according to the procedure of Maeda et al. (2002) using fresh raw milk obtained from the Holstein herd at the experimental farm. In brief, raw milk was skimmed by centrifugation and the resulting skim milk was acidified to $\mathrm{pH} 4 \cdot 6$ using $1 \mathrm{M}-\mathrm{HCl}$. The precipitates were removed by centrifugation to obtain acid whey followed by addition of $1 \mathrm{M}-\mathrm{NaOH}$ to adjust $\mathrm{pH}$ to $5 \cdot 0$. The acid whey was applied to DEAE-Sepharose CL-6B (Pharmacia, Uppsala, Sweden) equilibrated with $0 \cdot 1 \mathrm{M}$-acetate buffer $\mathrm{pH} 5 \cdot 0$. After washing off unadsorbed materials, elution was carried out by linear gradient of $\mathrm{NaCl}$ dissolved in the same buffer. The fraction containing OPN was pooled and dialysed against $0 \cdot 1 \mathrm{M}$-acetate buffer $\mathrm{pH} 5 \cdot 0$. Rechromatography was carried out using DEAE-Toyopearl $650 S$ (Tosoh, Tokyo, Japan) equilibrated with the same buffer, followed by elution with linear gradient of $\mathrm{NaCl}$ dissolved in the same buffer.

\section{Protein determination}

Protein concentration was determined by a modified Lowry method (Bensadoun \& Weinstein, 1976) using bovine serum albumin as a standard.

\section{Polyclonal antibodies}

Two polyclonal antibodies for human OPN (hOPN2 and hOPN4) were used (Kon et al. 2000). 


\section{Electrophoresis and immunoblotting}

Samples were loaded on to a $12 \cdot 5 \%$ polyacrylamide gel containing $0 \cdot 1 \%$ SDS according to the procedure of Laemmli (1970). Proteins in the gel were stained with 1-ethyl-2-[3-(1-ethylnaphtho[1,2d]-thiazolin-2-ylidene)-2methylpropenyl]naphtho[1,2d]-thiazolium bromide known as "Stains-All" (Eastman Organic Chemicals, NY, USA) according to the procedure of Green et al. (1973).

For immunoblotting analysis, proteins in the gel were electrophoretically transferred to a PVDF membrane (Osmonics, Westborough, MA, USA.) using a semi-dry system (Tanaka et al. 1999). The membrane was blocked by soaking in a solution of $1 \%$ bovine serum albumin (BSA) dissolved in phosphate-buffered saline (PBS) and the membrane was incubated with hOPN2 or hOPN4 dissolved in $1 \%$ BSA/PBS solution. Signals were detected using alkaline phosphatase-conjugated anti-rabbit immunoglobulin G and chemiluminescence with CDP-Star.

\section{Molecular properties of OPN against some enzymes}

Purified OPN was incubated with glycosidases or chymosin. Ten micrograms of the purified OPN was boiled for $5 \mathrm{~min}$ in the presence of $1 \%$ SDS and diluted 20-fold with $20 \mathrm{~mm}$-sodium phosphate buffer $(\mathrm{pH} \mathrm{7 \cdot 2)}$ containing $0.05 \%$ Triton $\mathrm{X}-100$. The resulting mixture was incubated at $37{ }^{\circ} \mathrm{C}$ for $18 \mathrm{~h}$ in the presence of $2 \mathrm{U}$ of $\mathrm{N}$-glycosidase $\mathrm{F}$ or $2.5 \mathrm{mU}$ of O-glycosidase supplemented with $5 \mathrm{mU}$ of sialidase. These enzymes were obtained from Roche (Mannheim, D-68305 Germany).

Sensitivity against calf chymosin was investigated by incubation of the purified OPN $(0 \cdot 25 \mathrm{mg})$ dissolved in $1 \mathrm{ml}$ of $20 \mathrm{~mm}$-PIPES (pH 6.2) containing $1 \mathrm{~mm}^{-\mathrm{CaCl}_{2}}$ in the presence of defined units $(0.01$ to $1 \cdot 0 \mathrm{U})$ of commercial recombinant chymosin known as MAXIREN (Gist-brocades, Seclin, 59472, France). In our study, rennet activity was determined by the procedure of Berridge (1945). The reaction was performed at $37^{\circ} \mathrm{C}$ for $3 \mathrm{~h}$ and terminated by the addition of $1 \%$ SDS-containing buffer prepared for electrophoresis.

\section{Isolation of fragments released from OPN by chymosin}

Purified OPN treated with $0 \cdot 1 \mathrm{U}$ of MAXIREN at $37{ }^{\circ} \mathrm{C}$ for 3,8 or $24 \mathrm{~h}$ was loaded on a CAP CELL PAK C8 column $(4 \cdot 6 \times 150 \mathrm{~mm}$; Shiseido Co., Ltd., Ginza, Japan). Alternatively, the MAXIREN-treated sample was fractionated using a centrifugal filter of Ultrafree-MC tube (Millipore, Bedford, MA 01730, USA) with a molecular weight cut-off of $10 \mathrm{kDa}$, at $1800 \mathrm{~g}$ at $4{ }^{\circ} \mathrm{C}$ for $30 \mathrm{~min}$ to obtain a filtrate. Experimental conditions were as previously described (Kumura et al. 1999).

\section{$N$-terminal amino acid sequence analysis}

$\mathrm{N}$-terminal amino acid sequence of the purified OPN and the fractions obtained by HPLC was determined using a
(A)

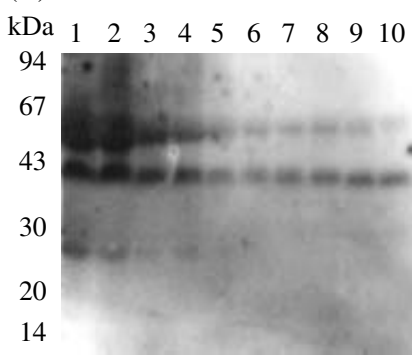

(B)

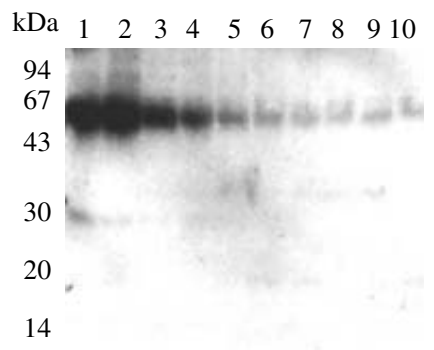

Fig. 1. Western blotting of mammary secretions during early lactation. Two microlitres of ten-fold diluted sample was loaded on each lane for SDS-PAGE and detected with hOPN2 (A) or hOPN4 (B). Lane 1, just after parturition (day 1 morning); lane 2, day 1 evening; lane 3, day 2 morning; lane 4, day 2 evening; lane 5 , day 3 morning; lane 6 , day 3 evening; lane 7 , day 4 morning; lane 8, day 4 evening; lane 9 , day 5 morning; lane 10 , day 5 evening.

protein sequencer (model 492A, Applied Biosystems, Foster City, CA, USA).

\section{Results and Discussion}

Results obtained by Western blot analysis using one representative sample of individual bovine mammary secretions taken during the first 10 milkings are shown in Fig. 1. Two distinct bands of 60 and $40 \mathrm{kDa}$ were recognized by the antibody hOPN2 (Fig. 1A). In contrast, a band of $60 \mathrm{kDa}$ was found when hOPN4 was used (Fig. 1B). The signal from the $60-\mathrm{kDa}$ band exhibited the same progressive decrease of intensity over time when using hOPN2 or hOPN4. Slight signals of $26 \mathrm{kDa}$ and $28 \mathrm{kDa}$ were detected using hOPN2 and hOPN4, respectively. However, these signals appeared less frequently and varied between individual cows.

To identify the 40-kDa signal detected by hOPN2, purification of OPN from bulk milk was performed. Analysis of the N-terminal amino acid sequence of purified OPN gave LPVKP, indicating that the OPN preparation was highly purified and contained negligible amounts of contaminants. Nevertheless, both signals of 60 and $40 \mathrm{kDa}$ were recognized when the purified OPN was analysed by Western blotting with hOPN2 (Fig. 2B, lane 3 and 4). It is interesting to note that hOPN2 was established using $\mathrm{N}_{18}-\mathrm{Q}_{34}$ as the epitopic region, whilst hOPN4 was prepared using $\mathrm{K}_{244}-\mathrm{N}_{262}$ as the epitopic region, which is located in the last C-terminal region (Kon et al. 2000). The $\mathrm{N}$-terminal sequence analysis of the purified OPN gave the result expected for intact mature bovine OPN. Therefore, it can be concluded that the signal observed at $40 \mathrm{kDa}$ was the result of a deletion of the C-terminal region of OPN. In human milk, a component of $35 \mathrm{kDa}$ appears in addition to intact OPN, which had a molecular mass of $75 \mathrm{kDa}$ (Senger et al. 1989). This 35-kDa component, predicted as the product of natural cleavage of OPN, may be analogous 

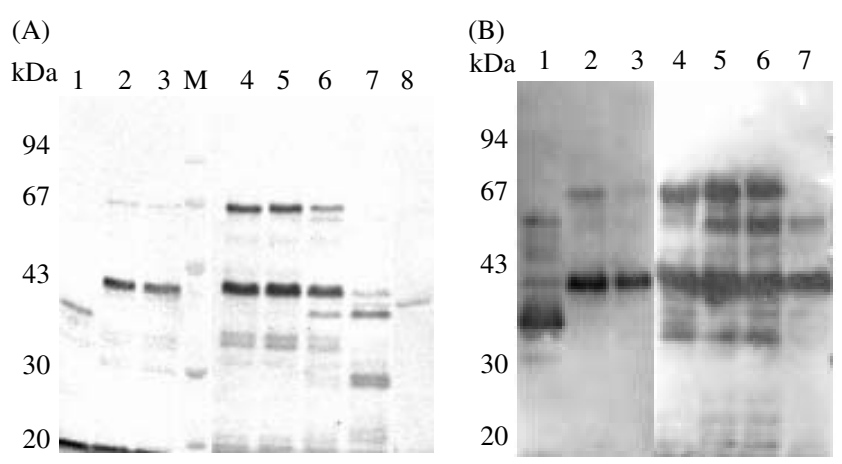

Fig. 2. Susceptibility of OPN to glycosidases and chymosin. Samples were loaded on each lane for SDS-PAGE and stained with Stains-All (A) or detected by Western blotting using hOPN2 (B). OPN incubated with O-glycosidase and sialidase (lane 1), OPN incubated with $\mathrm{N}$-glycosidase $\mathrm{F}$ (lane 2), purified OPN (lane 3 and 4), OPN incubated with 0.01 $\mathrm{U}$ of chymosin (lane 5), OPN incubated with $0 \cdot 1 \mathrm{U}$ of chymosin (lane 6), OPN incubated with $1 \mathrm{U}$ of chymosin (lane 7), $1 \mathrm{U}$ of chymosin (lane 8). $M=$ molecular mass marker comprising phosphorylase $b$ (97 kDa), Albumin (66 kDa), ovalbumin (45 kDa), carbonic anhydrase (30 kDa) and trypsin inhibitor (20 kDa).

to the $40-\mathrm{kDa}$ band observed in the present study. However, when proteins from rodent mammary gland tissue after $2 \mathrm{~d}$ of lactation are extracted and analysed, the corresponding polypeptide from OPN is not detected by Western blot analysis (Rittling \& Novick, 1997). This suggests that generation of the $35-40 \mathrm{kDa}$ derivative in mammary secretions depends on the animal species. In this study, the C-terminal counterpart was undetectable, which was attributed to its high susceptivity to proteolysis.

Further characterization of bovine OPN was performed with regard to glycosylation. The electrophoretic mobilities of both the 60- and 40-kDa OPN were unaffected by incubation of OPN with N-glycosidase (Fig. 2A and 2B, lane 2), whereas the molecular mass of these OPN decreased by $5-8 \mathrm{kDa}$ when O-glycosylation site(s) were eliminated (Fig. 2A and 2B, lane 1). Sørensen et al. (1995) report the presence of three O-glycosylated threonines $\left(\mathrm{Thr}_{115}, \mathrm{Thr}_{124}\right.$ and $\mathrm{Thr}_{129}$ ) and no N-glycosylation site in bovine milk OPN, despite the presence of three putative $\mathrm{N}$-glycosylation sites. Thus, our result demonstrated that three O-glycosylated threonines were retained in the 40-kDa OPN, which possessed more than 129 amino acid residues in the $\mathrm{N}$-terminal region of mature bovine OPN. Since the molecular mass of bovine OPN without any post-translational modification was predicted to be $29 \mathrm{kDa}$, the electrophoretic mobility of the glycosylated OPN should have been $35 \mathrm{kDa}$. However, the electrophoretic mobility was revealed to be slower than expected and this was attributed to the high degree of phosphorylation of OPN.

The biological significance of intact or partially digested OPN in milk has yet to be elucidated. The fact that OPN is abundant in colostrum and that chymosin appears

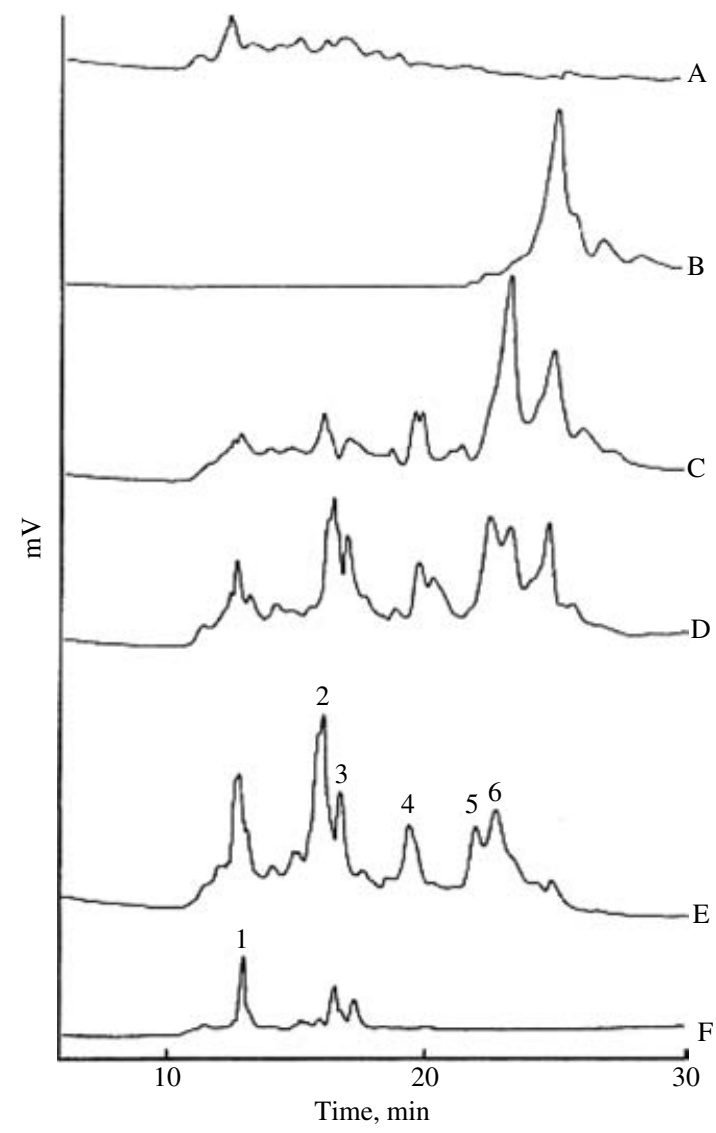

Fig. 3. HPLC elution of OPN treated with chymosin. Chromatogram represents chymosin (A), intact OPN (B), OPN incubated with $0 \cdot 1 \mathrm{U}$ of chymosin at $37^{\circ} \mathrm{C}$ for $3 \mathrm{~h}(\mathrm{C})$, for $8 \mathrm{~h}$ (D), for $24 \mathrm{~h}$ (E) and $24 \mathrm{~h}$ followed by fractionation using centrifugal filter $(\mathrm{F})$. The constituents of the numbered fractions were subjected to $\mathrm{N}$-terminal amino acid sequence analysis.

exclusively in the abomasum of newborn ruminants led us to speculate that the liberation of biologically active fragments from OPN could be induced by chymosin. When OPN was incubated with $0 \cdot 01 \mathrm{U}$ of chymosin, faint bands corresponding to molecular masses of $57 \mathrm{kDa}$ and $37 \mathrm{kDa}$ appeared (Fig. 2A, lane 5), which was more pronounced when OPN was incubated with $0 \cdot 1 \mathrm{U}$ of chymosin (Fig. 2A, lane 6). Deletion of $3 \mathrm{kDa}$ peptide may have occurred as the primary event in both the 60- and 40$\mathrm{kDa}$ form of OPN. Increasing proteolytic activity up to $1 \mathrm{U}$ led to the appearance of polypeptides of 28 and $29 \mathrm{kDa}$ in addition to accumulation of one of $37 \mathrm{kDa}$ (Fig. 2A, lane 7). These resulting fragments were shown to lack the $\mathrm{N}$-terminal region of intact OPN because they were undetectable by Western blotting using hOPN2 (Fig. 2B, lane 5-7). Conversely, $0 \cdot 01 \mathrm{U}$ of chymosin released a polypeptide of $50 \mathrm{kDa}$, which was poorly stained with StainsAll, but responsive to hOPN2 (Fig. 2A and 2B, lane 5). According to Foltmann (1971) $8.9 \times 10^{5}$ rennet units are obtained from 28 dried calf stomachs. Simply calculated, $3 \cdot 1 \times 10^{4}$ rennet units could be present in a single 
stomach. Therefore, it is conceivable that extensive degradation of colostral OPN would occur by the action of chymosin.

To identify cleavage sites, fractionation of fragments was attempted using HPLC. In this experiment, the amount of chymosin was reduced to $0 \cdot 1 \mathrm{U}$ in order to facilitate resolution of chymosin and, conversely, the incubation period was extended up to $24 \mathrm{~h}$. As shown in Figs $3 \mathrm{~B}-3 \mathrm{E}$, OPN was progressively digested and finally, multiple peaks were recognized (Fig. 3E). The peak of earlier retention time seemed to contain not only OPN fragment but also chymosin by comparison with the major peak of MAXIREN (Fig. 3A). Therefore, before applying it to the HPLC column, the sample was fractionated using a centrifugal filter whose cut-off molecular mass was $10 \mathrm{kDa}$. In the resulting filtrate, three peaks were found in the earlier retention time (Fig. 3F). Finally, we collected six numbered samples to determine the $\mathrm{N}$-terminal acid sequence.

Determination of peak No. 1 (Fig. 3F) identified the cleavage site of $\mathrm{I}_{26}-\mathrm{W}_{27}$ and peak No. 4 (Fig. 3E) was predicted to arise from $\mathrm{I}_{26}-\mathrm{W}_{27}$ and $\mathrm{R}_{152}-\mathrm{R}_{153}$. In peaks No. 2 and 3, the N-terminal amino acid sequence of mature OPN was recognized. Peak No. 5 contained peptides considered as SQEF and DDDDD, which corresponded to cleavage sites of $\mathrm{L}_{223}-\mathrm{S}_{224}$ and $\mathrm{L}_{72}-\mathrm{D}_{73}$, respectively. The latter sequence was found in peak No. 6 as well. Differences of susceptibility of the dual forms of OPN to chymosin remains unclear. In any case, the cleavage profile was concluded to be indefinite. However, in terms of its location and molecular mass, it could be postulated that the site of $\mathrm{I}_{26}-\mathrm{W}_{27}$ was preferentially cleaved by chymosin to release $57-\mathrm{kDa}$ and $37-\mathrm{kDa}$ OPN fragments. In the C-terminal region, site(s) sensitive to chymosin existed because of the presence of a 50-kDa fragment, responsible for hOPN2, although the cleavage site remained unclear.

Senger et al. (1989) report OPN concentration in human milk of 3-10 mg/l. From $1 \mathrm{l}$ of bovine milk, Sorensen and Petersen (1993) and Bayless et al. (1997) isolated approximately $22 \mathrm{mg}$ and $8 \mathrm{mg}$ of OPN, respectively. However, no information was available on the concentration of OPN in bovine colostrum or mature milk. Therefore we performed Western blotting of serial dilutions of seven colostrums and milks from the 10th milking post partum with reference to a known quantity of purified OPN. As a result, we measured $<200 \mathrm{mg} / \mathrm{l}$ in colostrum and at day 5 of lactation, it had decreased to less than $10 \%$ of its initial level. Consequently, the concentration of OPN was much lower than that of immunoglobulins or lactoferrin (Scammell, 2001), but the abundance of OPN in colostrum was confirmed.

In conclusion, we demonstrated effects of chymosin on OPN and confirmed the presence of intact and partially degraded OPN in mammary secretions. Further investigations are needed to elucidate the biological significance to the newborn of OPN and/or the fragments released by chymosin.
This work was supported in part by a grant from The MORINAGA HOSHI-KAI. The authors thank Sigeyuki Kon, Institute for Genetic Medicine, Hokkaido University (Sapporo, Japan) and Masahiro Maeda, Immuno-Biological Laboratories (Fujioka, Japan) for the gift of polyclonal antibodies, and Toshimitsu Uede, Institute for Genetic Medicine, Hokkaido University for helpful discussion. We also thank Hideshi Shinkai, Taro Takahashi, Norikazu Yamaki and Katsuro Taira at the Experimental Farm, Agro-Ecosystem Research Station, Field Science Center for Northern Biosphere, Hokkaido University for their assistance with sample preparation, and Yoshiko Miura and Seiko Ueda, Graduate School of Agriculture, Hokkaido University for technical assistance.

\section{References}

Bayless KJ, Davis GE \& Meininger GA 1997 Isolation and biological properties of osteopontin from bovine milk. Protein Expression and Purification 9 309-314

Bensadoun A \& Weinstein D 1976 Assay of proteins in the presence of interfering materials. Analytical Biochemistry 70 241-250

Berridge NJ 1945 The purification and crystallization of rennin. Biochemical Journal 39 179-186

Butler WT, Ridall AL \& McKee MD 1996 Osteopontin. In Principles of Bone Biology, pp. 167-181 (Eds JP Bilezikan, LG Raisz \& GA Rodan). San Diego, CA: Academic Press

Foltmann B 1971 The biochemistry of prorennin (prochymosin) and rennin (chymosin). In Milk Proteins: Chemistry and Molecular Biology II, pp. 217-254 (Ed. HA Mckenzie). New York \& London: Academic Press

Green MR, Pastewka JV \& Peacock AC 1973 Differential staining of phosphoproteins on polyacrylamide gels with a cationic carbocyanine dye. Analytical Biochemistry 56 43-51

Kon S, Maeda M, Segawa T, Hagiwara Y, Horikoshi $Y$, Chikuma S, Tanaka K, Rashid MM, Inobe M, Chambers AF \& Uede T 2000 Antibodies to different peptides in osteopontin reveal complexities in the various secreted forms. Journal of Cellular Biochemistry 77 487-498

Kumura H, Murata S, Hoshino T, Mikawa K \& Shimazaki K 1999 Autolysis of the proteinase from Pseudomonas fluorescens. Journal of Dairy Science 82 2078-2083

Laemmli UK 1970 Cleavage of structural proteins during the assembly of the head of bacteriophage T4. Nature 227 680-685

Maeda A, Ametani M, Azuma N \& Kanno C 2002 Simple method for purification of osteopontin and other milk protein components. Animal meeting of Japan Society for Bioscience, Biotechnology and Agrochemistry (Sendai) 112

Nemir M, Bhattacharyya D, Li X, Singh K, Mukherjee AB \& Mukherjee BB 2000 Targeted inhibition of osteopontin expression in the mammary gland causes abnormal morphogenesis and lactation deficiency. Journal of Biological Chemistry 275 969-976

Prince CW, Oosawa T, Butler WT, Tomana M, Bhown AS, Bhown M \& Schrohenloher RE 1987 Isolation, characterization, and biosynthesis of a phosphorylated glycoprotein from rat bone. Journal of Biological Chemistry 262 2900-2907

Rittling SR \& Novick KE 1997 Osteopontin expression in mammary gland development and tumorigenesis. Cell Growth and Differentiation 8 1061-1069

Salih E, Zhou HY \& Glimcher MJ 1996 Phosphorylation of purified bovine bone sialoprotein and osteopontin by protein kinases. Journal of Biological Chemistry 271 16897-16905

Scammell AW 2001 Production and uses of colostrum. Australian Journal of Dairy Technology $\mathbf{5 6}$ 74-82

Senger DR, Perruzzi CA, Papadopoulos A \& Tenen DG 1989 Purification of a human milk protein closely similar to tumor-secreted phosphoproteins and osteopontin. Biochimca et Biophysica Acta 996 43-48

Sodek J, Ganss B \& McKee MD 2000 Osteopontin. Critical Reviews in Oral Biology and Medicine 11 279-303 
Sørensen ES, Hojrup P \& Petersen TE 1995 Post-translational modifications of bovine osteopontin: identification of twenty-eight phosphorylation and three O-glycosylation sites. Protein Science 4 2040-2049

Sørensen ES \& Petersen TE 1993 Purification and characterization of three proteins isolated from the proteose peptone fraction of bovine milk. Journal of Dairy Research 60 189-197
Tanaka T, Xuan X, Kato M, Nagasawa H, Fujisaki K, Mikami T \& Suzuki N 1999 Expression of recombinant Toxoplasma gondii P24. Journal of Veterinary Medical Science 61 1235-1239

Uede T, Katagiri Y, lizuka J \& Murakami M 1997 Osteopontin, a coordinator of host defense system: a cytokine or an extracellular adhesive protein? Microbiology and Immunology 41 641-648 